This is the author's accepted manuscript of the below article published by Elsevier in Structural Change and Economic Dynamics, Vol 37 pp. 52-61 June 2016. Available online at: $\underline{10.1016 / i . s t r u e c o .2015 .12 .001}$

Downloaded from SOAS Research Online: http://eprints.soas.ac.uk/21916/

\title{
Production Complexity, Adaptability and Economic Growth
}

by

\section{Benno Ferrarini $i_{a}$}

${ }_{a}$ Economic Research and Regional Cooperation Department, Asian Development Bank, 6 ADB Avenue, Mandaluyong 1550, Metro Manila, Philippines

\author{
Pasquale Scaramozzino* ${ }_{b, c}$ \\ ${ }_{b}$ Department of Financial and Management Studies, SOAS University of London, \\ Thornhaugh Street, Russell Square, London WC1H OXG, UK \\ and \\ cDipartimento di Economia Diritto e Istituzioni, Università di Roma Tor Vergata,
}

Via Columbia 2, 00133 Roma, Italy

(*) Corresponding author: ps6@soas.ac.uk

October 2015

\begin{abstract}
This paper analyzes the impact of production complexity and its adaptability on the level of output and on its rate of growth. We develop an endogenous growth model where increased complexity raises the rate of economic growth but has an ambiguous effect on the level of output. Our empirical measure of production adaptability captures the proximity of production sectors within the product space, which we modify to reflect intra-industry trade and the international fragmentation of production. We test the model against a sample of 89 countries over the two decades to 2009 and find that its main predictions are validated.
\end{abstract}

Keywords: product space, production adaptability, economic growth

JEL Codes: F19, O14, O33, O47 


\section{Introduction}

A country's ability to develop and expand a set of complex production structures requires the availability of a broad skill set, or capabilities, that are adaptable to changing technology. The recognition of a causal link between the efficient division of labor and the gains from specialization goes back to Adam Smith (1776) and has found broad recognition since. For example, the role of capabilities as a precondition for long-term growth is central to the work of Hirschman (1958), where capabilities consist of backward and forward linkages across economic sectors. Similarly, Lewis (1955), Rostow (1959) and Kaldor (1967) portrayed economic development essentially as a process of structural transformation and increasing productivity that is driven by the progressive strengthening of productive capabilities, as well as by the reallocation of resources. Later, Lall (1992) and Kremer (1993) linked capabilities to economic growth and development through their impact on innovation. At the firm level of analysis, Sutton (2001) showed that modern economies' ability to exploit scarce capabilities is at the root of their development success.

Introducing the concept of product space, which maps and links products according to country characteristics necessary for their production, Hausman, Hwang, and Rodrik (2007) initiated an influential line of research that has sought to explain the relationship between country incomes, growth and a broad measure of production capacity or capabilities. They find evidence that a positive relationship exists between a country's set of capabilities and its rate of economic growth, and suggest that some goods have higher spillover effects than others. Expanding on this finding, Hidalgo and Hausman (2009) suggest that economic complexity spurs growth in countries that are below the income expected from their capability endowment and have yet to venture into developing the full range of products that is within their technological reach. Spillovers and potential growth are highest for countries producing the more complex goods, which are more tightly linked within the product space and facilitate expansion into a broader range of product lines and industries. Governments can address this market failure by tilting resource allocation toward more complex or sophisticated goods. Wang, Wei and Wong (2010) question the proposition that governments should pursue such a "leapfrogging growth strategy". They argue that empirical evidence in favor of government intervention is too scant, as various measures of export sophistication in their panel growth regressions are estimated to be statistically insignificant. However, subsequent analyses, such as in Felipe et al. (2012) and Poncet and de Waldemar (2013), are at odds with this conclusion and find that complexity exerts a positive impact on economic growth. 
Such track record notwithstanding, the concept of capabilities has not entered the mainstream literature of economic growth. Indeed, the neoclassical growth model (Solow, 1956) treats technology and its complexity as exogenous, and the endogenous growth models either account for technological change (Romer, 1989) or human capital (Lucas, 1988), but not for production complexity and capabilities as such, which are ignored. In view of this gap, in this paper we set out a growth model that is driven by human capital accumulation as well as by trade specialization and complexity, building on Costinot (2009). We gauge complexity through an aggregate measure of production adaptability derived from a modified (net trade) Hausman and Klinger $(2006,2007)$ product space. In this approach, economic development involves countries striving to upgrade their complex set of capabilities in order to expand production into the newly attainable sectors associated with higher productivity. This process in turn enhances their set of capabilities so that the next tier of proximate sectors will become attainable over time (Hidalgo, Klinger, Barabási and Hausmann, 2007; Hidalgo and Hausmann, 2009; Hidalgo, 2009; Ferrarini and Scaramozzino, 2015).

In our model, an increase in production complexity plays a dual role. On the one hand, it enhances human capital accumulation through the advancement of skills and the promotion of learning (Lucas, 1988 and 1993). On the other, it heightens the risk of production failure through an increase in the number of tasks that need be executed correctly for the product to finalize. Consistent with Kremer's (1993) O-ring theory, a more complex technology entails a higher risk of failure because it lowers the probability that all of the required tasks are performed correctly.

Our theoretical framework thus implies that complexity impacts the level of output and its rate of growth through two separate channels, and possibly in opposite directions. While increased complexity is always associated with a higher long-run rate of growth, at any given time it may either increase or decrease the level of output, depending on whether or not the gains from specialization will outweigh the losses associated with production failures.

We test these predictions against a data set spanning 89 countries from 1990 to 2009 . The focus of our empirical investigation is the relation between production adaptability and output. To do so, we devise a measure of average country density that proxies for production adaptability and complexity to an extent. Controlling for human capital and the other key drivers of economic growth identified in the literature, our findings suggest that countries with more adaptable production systems experience higher output growth. Moreover, country density is found to yield a negative impact on economic output, which suggests that, in levels, the losses outweigh the gains from greater specialization. 
The remainder of the paper defines, in Section 2, the endogenous growth model with human capital accumulation and complexity. Section 3 derives our trade-based measure of complexity and adaptability and extends the empirical framework to account also for the role of international production networks and vertical trade. Section 4 turns to the regressions of country density on output level and growth. Section 5 concludes.

\section{Complexity, human capital and growth}

Technological complexity and economic capabilities can play a crucial role for the economic performance of a country. The way they interact can be explained with the aid of an endogenous growth model with human capital accumulation, heterogeneous industries, and complementarities in the production technology. The main motivation for the analysis is that technological complexity can be critical for the development of new skills and for human capital formation, which are the fundamental drivers of growth in the long run. We set out a very flexible specification, which makes it possible to consider the multiple potential effects of complexity both on the level and on the rate of growth of output.

Accumulation of human capital is modeled following Lucas (1998, 1993). Workers decide how much of their time should be allocated to current production and to the formation of human capital, which would increase their future productivity. Differently from the original model by Lucas, industries are not identical but each is characterized by a different level of complexity in its production technology. Greater complexity could be associated with a reduction in industry output: production requires the execution of a certain number of complementary tasks, and a greater degree of complexity increases the risk of failure in the production process (as in the O-ring production function: Kremer, 1993). On the other hand, it could have a positive effect on output because it can be associated with a more advanced region in the product space (Hidalgo, Klinger, Barabási and Hausmann, 2007; Ferrarini and Scaramozzino, 2015). A higher average level of complexity would always have a beneficial effect on the rate of growth of the economy, because it enhances the accumulation of human capital. Hence, whilst the consequence of greater complexity on the level of output could be ambiguous, its effect on the rate of growth of the economy is always positive.

In each country $c=1,2, \ldots, N$, the size of the labor force is fixed at $L_{c}$. The average level of human capital in country $c$ is $h_{c}$ : for the sake of simplicity, this is assumed to be constant across all industries in the economy. The share of non-leisure time allocated to current production is denoted by $\lambda_{c} \in[0,1]$, with the complementary share $1-\lambda_{c}$ being 
allocated to human capital formation. Investment in human capital is the key driver for the growth prospects of the economy in the long run.

In each country there is a continuum of industries $i$, which are uniformly distributed over the unit interval: $i \sim U[0,1]$. Each industry is characterized by a parameter $z^{i} \geq 0$, which captures the technological complexity of the industry. This complexity determines the location of the industry in the product space and is associated with a more advanced production technology. Higher complexity is related to the division of labor and hence to the number of tasks that are involved in the production process. In this respect, an increased number of tasks could result in gains from the specialization of labor (as in Costinot, 2009), but at the same time could reduce the probability that they are all jointly correctly executed (Kremer, 2003; Dalmazzo et al., 2007). Hence, increased complexity could have an ambiguous consequence on industry output, depending on whether the predominant effect is through the product space or through the complementarity mechanism.

It is assumed that the degree of complexity of an industry is a technological characteristic of that particular industry and that it is constant across countries. The economies will however differ in terms of the moments of the statistical distribution of industries in the complexity space.

Output of industry $i$ in country $c$ is expressed as:

$$
Q_{c}^{i}=\lambda_{c} h_{c} e^{\alpha_{c} z^{i}}
$$

The level output is an increasing function of the time allocated to current production $\lambda_{c}$ and of human capital $h_{c}$. It is also a function of the complexity of industry $i, z^{i}$, through the parameter $\alpha_{c} \equiv \theta_{c}-\delta_{c}$, where $\theta_{c} \geq 0$ captures the potential positive product-space effect of complexity on output and where $\delta_{c} \geq 0$ expresses the possible negative influence from the O-ring complementarities in production. In principle, $\alpha_{c} \gtreqless 0$ : the net effect of complexity on the level of output depends on whether either the product-space or the O-ring effect dominates. The multiplicative/exponential functional form is chosen for its analytical convenience.

Let $\varphi_{c}\left(z^{i}\right)$ be the density function of complexity in country $c$. Total output of country $c$ is thus:

$$
Q_{c}=L_{c} \int_{0}^{\infty} Q_{c}^{i} \varphi_{c}\left(z^{i}\right) d z^{i}
$$


For analytical tractability, we assume that industry complexity $z^{i}$ in country $c$ has a general gamma distribution with parameters $k_{c}>0$ and $\beta_{c}>0: z^{i} \sim \operatorname{Gamma}\left(k_{c}, \beta_{c}\right)$, or:

$$
\varphi_{c}\left(z^{i}\right)=\frac{1}{\beta_{c}^{k_{c}} \Gamma\left(k_{c}\right)}\left(z^{i}\right)^{k_{c}-1} e^{-z^{i} / \beta_{c}}, \quad z^{i} \geq 0
$$

From the properties of the gamma distribution, average complexity in country $c$ is given by $z_{c}=E_{c}\left(z^{i}\right)=k_{c} \beta_{c}$, its variance by $V_{c}\left(z^{i}\right)=k_{c} \beta_{c}^{2}$ and its skewness by $2 / \sqrt{k_{c}}$. In the density function (3), $k_{c}$ represents the shape parameter and $\beta_{c}$ the scale parameter of the gamma distribution. We interpret the shape coefficient $k_{c}$ as a technological parameter, associated with the production characteristics of the industry and constant across countries: $k_{c}=k, c=1,2, \ldots, N$. The parameter $\beta_{c}$ has instead the effect of scaling the graph of the distribution both horizontally and vertically. It is associated with the specific distribution of complexity in each individual country and is therefore country specific. Average complexity in country $c$ is thus given by $z_{c}=k \beta_{c}$.

Replacing (1) and (3) into (2), the level of output of country $c$ can be expressed as ${ }^{1}$ :

$$
Q_{c}=L_{c} \lambda_{c} h_{c} \cdot \frac{1}{\left(1-\alpha_{c} \beta_{c}\right)^{k}}
$$

From (4), the effect on output of the country-specific complexity parameter $\beta_{c}$ is ambiguous and depends on the sign of the parameter $\alpha_{c} \equiv \theta_{c}-\delta_{c}$. If the positive product-space effect of complexity dominates, then $\alpha_{c}>0$ and greater complexity is associated with increased output. By contrast, if the negative O-ring effect from complexity is predominant then $\alpha_{c}<0$ and greater complexity is associated with a lower level of output.

The human capital formation equation is based on Lucas $(1988,1993)$ :

$$
\dot{h}_{c}=\mu_{c}\left(1-\lambda_{c}\right) z_{c} h_{c}
$$

\footnotetext{
${ }^{1}$ The specification in equation (4) implies positive scale effects. In general, when the elasticity of substitution between production factors is different from one, it is possible to have negative scale effects for poor economies (Zuleta, 2004). The substitutability between production inputs is not one of the main concerns of our analysis. Instead of incorporating it directly into our model, we shall refer to it in our discussion of the empirical results in section 4 .
} 
where the parameter $\mu_{c}>0$ measures the effectiveness of the training system in country $c$. Relative to the original formulation by Lucas, human capital formation now includes average complexity $z_{c}$ as one of the arguments of the accumulation equation, alongside the initial level of human capital. Endogenous growth is secured by the assumption of constant returns with respect to human capital in the accumulation equation (5).

Output growth is given by: ${ }^{2}$

$$
\frac{d Q_{c}}{d t}=L_{c} \lambda_{c} \cdot \frac{1}{\left(1-\alpha_{c} \beta_{c}\right)^{k}} \cdot \frac{d h_{c}}{d t}=L_{c} \lambda_{c} \cdot \frac{1}{\left(1-\alpha_{c} \beta_{c}\right)^{k}} \cdot \mu_{c}\left(1-\lambda_{c}\right) z_{c} h_{c}
$$

and thus the instantaneous output growth rate must coincide with the rate of growth of human capital:

$$
g_{c} \equiv \frac{d Q_{c}}{d t} \cdot \frac{1}{Q_{c}}=\mu_{c}\left(1-\lambda_{c}\right) z_{c}=\mu_{c}\left(1-\lambda_{c}\right) k \beta_{c}=\frac{\dot{h}_{c}}{h_{c}}
$$

From equation (4), the level of output $Q_{c}$ is an increasing function of the size of the labor force $L_{c}$, of the time allocated to current production $\lambda_{c}$, and of average human capital $h_{c}$. The role of complexity $z_{c}$ depends on the interaction of the scale parameter of the gamma distribution, $\beta_{c}$ (since $z_{c}=k \beta_{c}$ ), with the parameter $\alpha_{c}=\theta_{c}-\delta_{c}$ in the production function (1). In particular, increased complexity could exert a negative effect on the level of output if $\alpha_{c}$ is negative, i.e. if $\theta_{c}<\delta_{c}$ and the O-ring effect dominates over the gains from specialization.

From the human capital formation (5) and from equation (7), the dynamic effects on the growth rate of output $g_{c}$ are an increasing function of the time allocated to human capital formation $\left(1-\lambda_{c}\right)$, of the quality of the educational system $\mu_{c}$, and of the average degree of complexity of the economy measured by $\beta_{c}$.

Thus, while increased complexity is always associated with an increase in the rate of growth of the economy, its role on the level of output is in principle ambiguous and depends on whether either the gains from specialization or the O-ring effects are predominant.

\footnotetext{
${ }^{2}$ Equation (6) assumes that average complexity of each country is constant over time. This disregards the dynamics of complexity, as countries diversify into new sectors and the distribution of the production complexity of their industries may change as a result. However, this simplifying assumption is thought to have little bearing on the empirical analysis below. For the sample period under consideration (spanning from1990 to 2009 ) is too short to allow for regressions of sub-periods and to test for changes in complexity over time. (The authors are indebted to an anonymous referee for raising this point.)
} 


\section{Complexity, production adaptability and trade}

Our measure of complexity and production adaptability is based on the product space approach by Hausmann and Klinger (2006, 2007). Instead of Heckscher-Ohlin's focus on resource endowments and Ricardian differences in technology, the product space approach associates a country's comparative advantage and trade specialization with its access to production capabilities. A country's profile of specialization and capabilities is thus gauged from its position in the product space, which itself is derived from the pattern of revealed comparative advantage observed across the trading nations.

In Hausmann and Klinger's (2006) analogy, the product space or forest is made of sectors or trees that are inhabited by countries' firms or monkeys. At a distance the monkeys cannot jump from one tree to another. That is, a country will find it impossible to get its economy diversified and its firms venturing into new sectors and products. By contrast, two or more goods or trees positioned close to each other entail similar prerequisites in terms of the capabilities which a country must possess in order to obtain a position of comparative advantage in the production and export of these goods. Therefore, specialization in either of these goods is expected to extend to connected sectors as well.

Sector crossing is facilitated in areas that are tightly clustered and where countries are able to develop and adapt their set of capabilities to the manufacture of a broad range of products characterizing those areas of the product space. A country's presence in the highly dense areas of the product space is thus a measure of the adaptability of its productive structure and the set of capabilities underlying it. ${ }^{3}$ For the empirical analysis in this paper, we devise a measure of average sector density that proxies for production adaptability. This rests on the premise that a country with a high average sector density must be in possession of a suitable set of capabilities that enabled its access and occupation of the denser and more complex areas of the product space.

Hausmann and Klinger (2006) compute the product space based on the Balassa revealed comparative advantage indicator, which relates a product's weight in a country's export basket to its weight with respect to some reference area, typically the world. This approach does not reveal countries' involvement in cross-border production networks, which blurs the attribution of revealed comparative advantage across countries. For example, a country's revealed comparative advantage in certain goods that embody capabilities previously imported from foreign suppliers cannot be fully ascribed to that country's own

\footnotetext{
${ }^{3}$ Product space density and related measures have found broad validation in the applied literature, such as in the growth diagnostic studies undertaken by the Asian Development Bank (ADB, 2009).
} 
pool of productive capabilities available. ${ }^{4}$ Unfortunately, international supply networks and value added trade accounting requires multiregional input-output tables, which are becoming available but do not yet offer sufficient detail at the level of products. To simply capture the portion of parts and components trade occurring within industries, we compute the product space that nets out parts and components trade at the level of 4-digit Harmonized System product categories.

Specifically, we adopt the Lafay (1992) index of specialization based on net exports to compute the product space, in contrast to the Balassa (1965) exports-based revealed comparative advantage indicator used in Hausmann and Klinger (2006) and subsequent analyses. ${ }^{5}$ The starting point for our product space is the normalized trade balance, defined as:

$$
z(c, i)=\frac{x(c, i)-m(c, i)}{x(c, i)+m(c, i)}
$$

where $x(c, i)$ are exports of industry $i$ in country $c$ and $m(c, i)$ are imports. The trade specialization index for each sector is computed as the difference between a country's normalized sector trade balance and its total trade balance, across sectors:

$$
T S(c, i)=z(c, i)-\sum_{i} z(c, i)
$$

The Lafay index, $\operatorname{LF}(c, i)$, is obtained by weighing the trade specialization index $\operatorname{TS}(c, i)$ by the sectoral contribution to trade:

$$
L F(c, i)=T S(c, i) \cdot \frac{[x(c, i)+m(c, i)]}{X(c)+M(c)}
$$

where $X(c) \equiv \sum_{i} x(c, i)$ and $M(c) \equiv \sum_{i} m(c, i)$. A positive value of the Lafay index, $L F(c, i)>0$, indicates that country $c$ specializes in sector or product category $i$.

\footnotetext{
${ }^{4}$ For a fuller discussion, see Ferrarini and Scaramozzino, 2015. The literature unambiguously points to a rapid expansion of production networks and vertical trade in the global economy, particularly since the early 1990s. Nowhere has the expansion of vertical trade networks and supply chains been more pronounced than in East Asia, particularly after China's rise as a global hub of manufacturing during the 2000s. By 2007, more than half of China's exports value represented value added imported from other countries (Koopman et al., 2008). Duernecker, Meyer and Vega-Redondo (2012) provide evidence on the importance of the integration of an economy into the global trade network for its rate of growth.

${ }^{5}$ Our definition of the indicator is based on the version of Lafay's index defined in Bugamelli (2001): see also Zaghini (2005), Alessandrini et al. (2011), and Ferrarini and Scaramozzino (2015).
} 
An indicator of trade specialization is then defined for sector $i$ of country $c$, as a binary variable that takes value 1 if country $c$ is specialized in sector $i$ and value 0 otherwise:

$$
q(c, i)=I(L F(c, i) \geq 0)=\left\{\begin{array}{lll}
1 & \text { if } & L F(c, i) \geq 0 \\
0 & \text { if } & L F(c, i)<0
\end{array}\right.
$$

The degree of closeness of any two production sectors $i$ and $j$ in the global product space is measured by the index of proximity $\theta(i, j)$ :

$$
\theta(i, j)=\min \{P(q(c, i)=1 \mid q(c, j)=1), P(q(c, j)=1 \mid q(c, i)=1)\}
$$

The index of proximity between sectors $i$ and $j$ is inversely related to the distance between the sectors, measured in terms of the conditional probabilities of trade specialization in the global product space ${ }^{6}$.

Finally, we compute the density index for sector $i$ in country $c$ as a weighted average of the trade specialization indicators, where the weights are the proximities of sector $i$ with all the other sectors:

$$
\omega(c, i)=\frac{\sum_{j} \theta(i, j) q(c, j)}{\sum_{j} \theta(i, j)}
$$

The average density of country $c$ is obtained as an average of the density indexes across all sectors:

$$
\bar{\omega}(c)=\sum_{i} \omega(c, i)
$$

Whilst density $\omega(c, i)$ measures a good's distance in the product space from the sectors associated with a country's export basket, the average density of a country $\bar{\omega}(c)$ relates to the adaptability of that country's production structure across all sectors. Put differently, it refers to the number of paths out of all possible paths within the product space that lead to the products that are already part of a country's export basket. Average density measures how fungible a country's capabilities are in terms of adjustment to complex production structures,

\footnotetext{
${ }^{6}$ See Hausmann and Klinger (2006) for a motivation of the index of proximity (12) and for a discussion of its properties.
} 
resulting from a country's exposure over time to increasingly complex production technologies and combinations of productive resources as it climbed the development ladder or, analogously, hopped trees across the product space.

Hidalgo and Hausmann (2009) and Hidalgo (2009) define product space complexity as a measure of diversification and product ubiquity. Diversification is the number of products a country exports with RCA. Ubiquity is the number of countries exporting a product with RCA. The more products a country produces (the more diversified it is) the more complex it is. The more countries export a product (the more ubiquitous it is) the more complex it is. A more diversified country has more capabilities necessary to produce a broader range of goods. A good that is less ubiquitous requires more exclusive capabilities. Complexity reflects the set of capabilities available to an economy and the capabilities required by a product. Overall country complexity reflects its degree of diversification and ubiquity of the products it specializes in.

In the product space, density and complexity are strongly related. Chemicals, machinery, electrical, plastics and rubbers, and metal products are the most complex products, which are located in the densely connected core. The least complex product groups are footwear, textiles, vegetable products, hides and skins, leathers and furs, foodstuffs, and animal products, which are found in the less connected periphery of the product space (Felipe et al. 2012). Countries occupying the denser parts of the product space are more complex and their capabilities more adaptable than countries occupying the sparse areas (Hidalgo and Hausmann 2009; Felipe et al. 2012).

It should be noted that our revised concept of product space and the related density measure account for intra-industry trade within coarse-grained sector balances. To account also for vertical trade in the empirical investigation of the complexity-growth model, we employ the Network Trade Index (NTI) as a measure of the intensity of trade among countries participating in the international production networks (Ferrarini, 2013). The NTI is defined as the share of supplier $j$ 's components of industry $s$ in country $i$ 's total imports of parts and components, weighted by the share of industry $s$ in country $i$ 's total final good exports. Specifically, denote by $c_{s}^{j}$ the value of imports to country $i$ of components of industry $s$ from country $j$. The total imports of components from sector $s$ to country $i$ is $\sum_{j} c_{s}^{j}$, and the share of country $j$ 's components of industry $s$ on total imports of $s$ in $i$ is $c_{s}^{j} / \sum_{j} c_{s}^{j}$. Let us further denote by $p_{s}^{i}$ the exports of $s$ from country $i$. The NTI for trade partner $j$ of country $i$ is then expressed as: 


$$
N T I^{j \mid i}=\sum_{s} \sum_{j \neq i} \frac{c_{s}^{j}}{\sum_{j} c_{s}^{j}} \cdot \frac{p_{s}^{i}}{\sum_{s} p_{s}^{i}}
$$

where $p_{s}^{i} / \sum_{s} p_{s}^{i}$ is the share of sector $s$ on total exports from country $i$. A higher value of NTI indicates a greater importance of country $j$ in the network of industrial relations of country $i$.

In its aggregate form, the index is derived as a geometric average across sectors and is normalized to range from 0 to 1 :

$$
\widetilde{N T I}=\frac{N T I-N T I_{\min }}{N T I_{\max }-N T I_{\min }}
$$

\section{Production adaptability: output level and growth regressions}

The theoretical model set out in section 2 yields predictions for the effects of increased complexity in the production process. A greater degree of complexity could in principle exert either a positive or a negative effect on the level of output, because of the potential trade-off between the gains from specialization and the O-ring effects. On the other hand, greater complexity should have a positive effect on output growth because it enhances the process of accumulation of human capital.

We test the predictions of the theoretical model — with production adaptability as a proxy for complexity — on a cross-section of 89 countries over the period 1990-2009 (see the Data Appendix for a full list of the countries included in the sample and for a description of the data sources). We estimate both level and growth equations for GDP per capita over periods of five years each: 1990-1994, 1995-1999, 2000-2004, and 2005-2009. As discussed in section 3, focus of the empirical investigation is countries' production adaptability as is captured by the average product density by country according to the Lafay product space, defined in equation $(14)^{7}$. The size of the labor force is measured by total active population aged 15 or over. The time allotted to current production is proxied by the labor force participation rate, and average human capital by the number of years of schooling (Barro and Lee, 2010) ${ }^{8}$.

\footnotetext{
${ }^{7}$ We also performed the statistical analysis using the Balassa definition of the product space, which leaves the main results unchanged. Additional regression results are available from the authors upon request.

${ }^{8}$ See the Data Appendix for a description of all the variables used in the analysis.
} 
Figure 1 illustrates the (unconditional) relationship between density in the product space and GDP per capita: higher density is generally associated with higher GDP per capita on average. Exceptionally high density is associated with countries that heavily engage in the Asian production networks, such as China, Hong Kong, Thailand, and India to an extent. This is by effect of density measures having been derived from the Lafay product space, which puts greater weight on the vertical proximity among product groups or sectors, thus on countries involved in international production networks. ${ }^{9}$

Figure 1. GDP per capita and density (logarithmic scale, averages across periods)

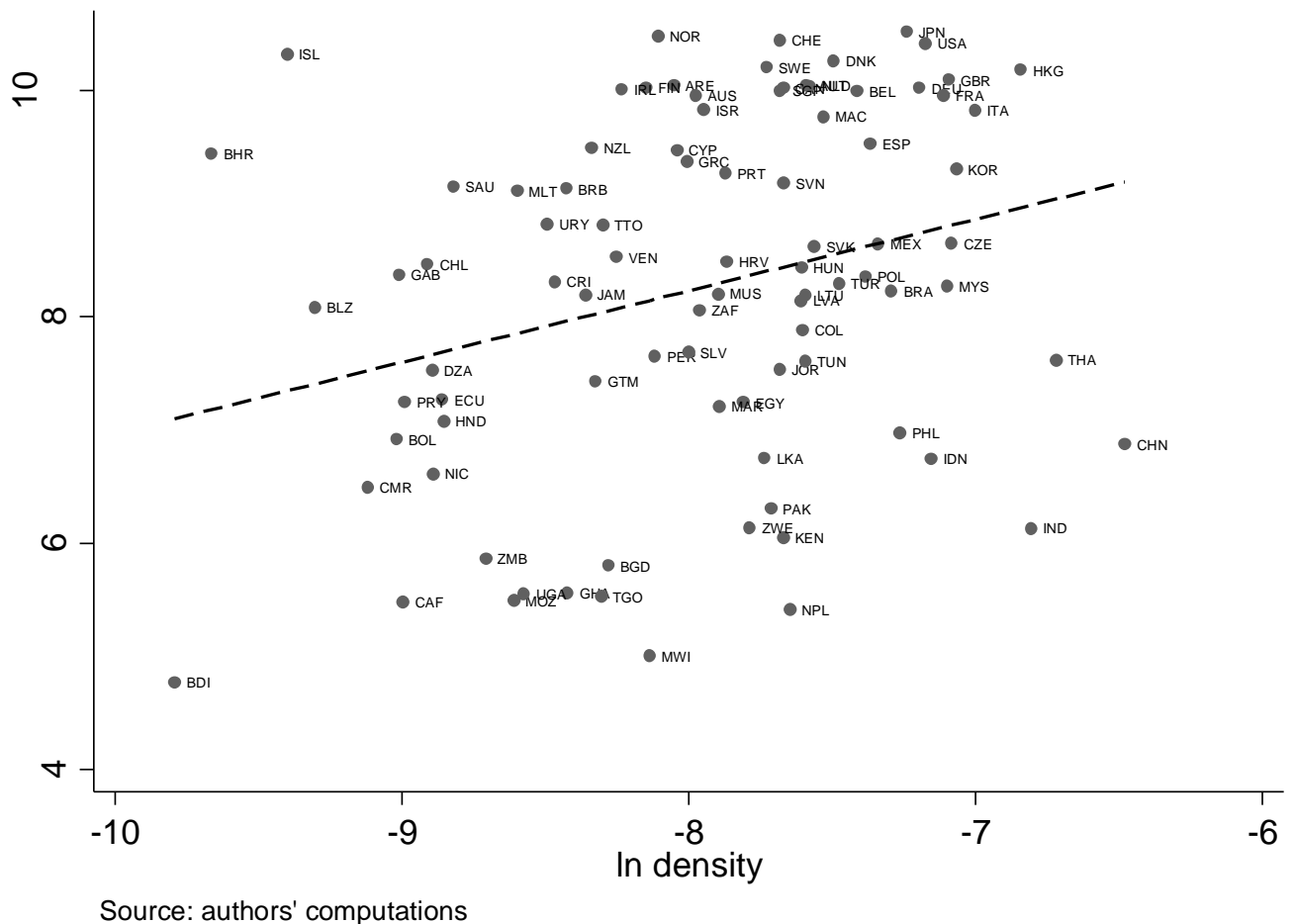

The direction of this relationship is conditional on a number of controls. This emerges from Table 1, which summarizes the results from regressions in levels, with the logarithm of GDP per capita as the dependent variable. The model is estimated by panel data Correlated Random Effects (CRE), which can be interpreted as encompassing Fixed Effects (FE) and Random Effects (RE) as special cases (Wooldridge, 2010, Chapter 10). ${ }^{10}$ Estimation by CRE

\footnotetext{
${ }^{9}$ Compared to the Balassa-based product space computation, the Lafay measure puts heavier weight on net trade balances between product categories, thus network trade, as opposed to within product categories, which are netted out. While this further raises density associated with mostly countries and East Asia it should be noted that Hausmann and Klinger (2007) themselves found that these countries tend to be specialized in a very dense part of the product space.

${ }^{10}$ The empirical specification of the model is based on log-linear approximations to the level equation (4) and to the growth equation (7). A log-linear specification is more likely to yield robust results than a direct estimation of the non-linear relationships (4) and (7), due to the relatively short time period and to the number of observations.
} 
requires that the unit-specific time averages of the explanatory variables are included among the regressors. The CRE estimators of the regression coefficients coincide with the corresponding FE estimators. Explanatory variables are the average density for the country in the product space (ldensity), total active population (llabf), labor force participation rate (llabfpr), and years of schooling (lschool). All the variables are expressed in logarithmic form. The regressions are estimated over the four sub-periods 1990-1994, 1995-1999, 20002004, and 2005-2009.

We perform Durbin-Wu-Hausman tests—reported in the second last rows of Tables 1 and 2-which for all the regressions soundly reject the null hypothesis that the random effects model is to be preferred on the grounds of its superior efficiency. However, the Hausman test is valid only under homoscedasticity. We therefore specify the fixed effects model through the inclusion of time averages for all the time-varying regressors and Wald test the null hypothesis that their estimates jointly equal zero (Wooldridge, 2010). The chisquared Wald statistics, reported in the last rows of Tables 1 and 2, clearly reject the hypothesis that the specific effects are really unrelated effects, thus validating the fixed-effect approach.

Table 1: Regressions in levels (lpcgdp), correlated random effects.

\begin{tabular}{|c|c|c|c|c|c|}
\hline Variable & $\begin{array}{c}\text { All } \\
\text { countries }\end{array}$ & $\begin{array}{l}\text { High } \\
\text { Income }\end{array}$ & $\begin{array}{c}\text { Middle \& } \\
\text { Low Income }\end{array}$ & \multicolumn{2}{|c|}{$\begin{array}{c}\text { All countries } \\
\text { with NTI available }\end{array}$} \\
\hline ldensity & $-0.050 * * *$ & $-0.187 * * *$ & $-0.046 * * *$ & $-0.081 * *$ & $-0.099 * * *$ \\
\hline llabf & $0.480 * * *$ & $0.920 * * *$ & $0.503 * * *$ & $0.757 * * *$ & $0.743 * * *$ \\
\hline llabfpr & $-0.683^{* * *} *$ & -0.157 & $-2.188 * * *$ & $-1.476 * * *$ & $-1.462 * * *$ \\
\hline lschool & $0.523 * * *$ & $0.363 * *$ & $0.357 * * *$ & $0.703 * * *$ & $0.662 * * *$ \\
\hline $\operatorname{lnti}$ & & & & & $0.577 * * *$ \\
\hline constant & $10.239 * * *$ & $-3.470 * * *$ & $18.012 * * *$ & $8.013 * * *$ & 0.699 \\
\hline $\begin{array}{l}\text { Means of time- } \\
\text { varying variables }\end{array}$ & YES*** & YES*** & YES*** & YES*** & YES*** \\
\hline Observations & 355 & 156 & 199 & 232 & 232 \\
\hline Countries & 89 & 39 & 50 & 58 & 58 \\
\hline Hausman Chi2 (/1) & $486.11 * * *$ & $82.42 * * *$ & $58.74 * * *$ & $169.87 * * *$ & $81.70 * * *$ \\
\hline Wald Chi2 (/2) & $642.71 * * *$ & $112.17 * * *$ & $305.78 * * *$ & $147.70 * * *$ & $205.76 * * *$ \\
\hline $\begin{array}{ll}\text { Legend: } & * \mathrm{p}<0.05 ; * * \mathrm{p}< \\
\text { Notes: } & (/ 1) \text { Hausman } \mathrm{C} \\
& \text { model is preferr } \\
& \text { reported here bu } \\
& (\text { /2) All the regr } \\
& \text { reported in this } \\
& \text { regressors joint }\end{array}$ & $\begin{array}{l}1 ; * * * p<0.001 \\
\text { refers to the trac } \\
\text { Underlying this } \\
\text { vailable on reque } \\
\text { ions include peri } \\
\text { le. Wald Chi2 is } \\
\text { qual zero. }\end{array}$ & $\begin{array}{l}\text { hal Durbin-W } \\
\text { are batteries }\end{array}$ & $\begin{array}{l}\text { vs. RE reg } \\
\text { essors, the e }\end{array}$ & $\begin{array}{l}\text { ull hypothes } \\
\text {; the coeffic } \\
\text { d coefficien }\end{array}$ & $\begin{array}{l}\text { at the random effect } \\
\text { s of which are not } \\
\text { which are not } \\
\text { sof the average }\end{array}$ \\
\hline
\end{tabular}


Column (1) of Table 1 shows the estimated coefficients for the regressions including all the 89 countries in the dataset. Density has a negative and significant coefficient on GDP per capita, which suggests that the O-ring effect outweighs the gains from specialization associated with countries occupying the denser areas of the product space where production adaptability is higher. In line with model predictions, the size of total active population affects level output positively. Also positive is the coefficient on the schooling variable, our proxy for economies' human capital endowment. This echoes the broader findings in the endogenous growth empirics, where human capital is typically found exerting a positive impact on per capita output. Interestingly, the coefficient on the labor force participation rate attracts a negative sign. This may be related to the possible low substitutability between production factors in poorer economies (Zuleta, 2004). In order to investigate this, columns (2) and (3) report regressions separating countries by income category. Coefficients are largely consistent with full sample estimates, but labor force participation is highly negative in the regression on developing countries only while lacking statistical significance in the regression involving high income countries. These regressions also show that density and the size of the labor market have a stronger average impact on countries of high income.

The NTI in logarithmic form, controlling for global supply chains, is included in the regressions in columns (4) and (5) as an additional explanatory variable. The sample now comprises 58 countries, instead of 89 , due to data limitations for the computation of NTI. Different sample size is the only difference between the estimates reported in the first and fourth column of Table 1, and the results are very similar. The coefficient on NTI in the last column provides evidence that a country's integration in the vertical trade networks is associated with a higher level of output. The coefficients on the core explanatory variables are largely the same as those in the regression without NTI. In particular, the density coefficient is now estimated at close to $10 \%$, corroborating a significantly negative relationship between complexity and growth after controlling for vertical network trade.

Figure 2. Growth of GDP per capita and density (logarithmic scale, averages across periods). 


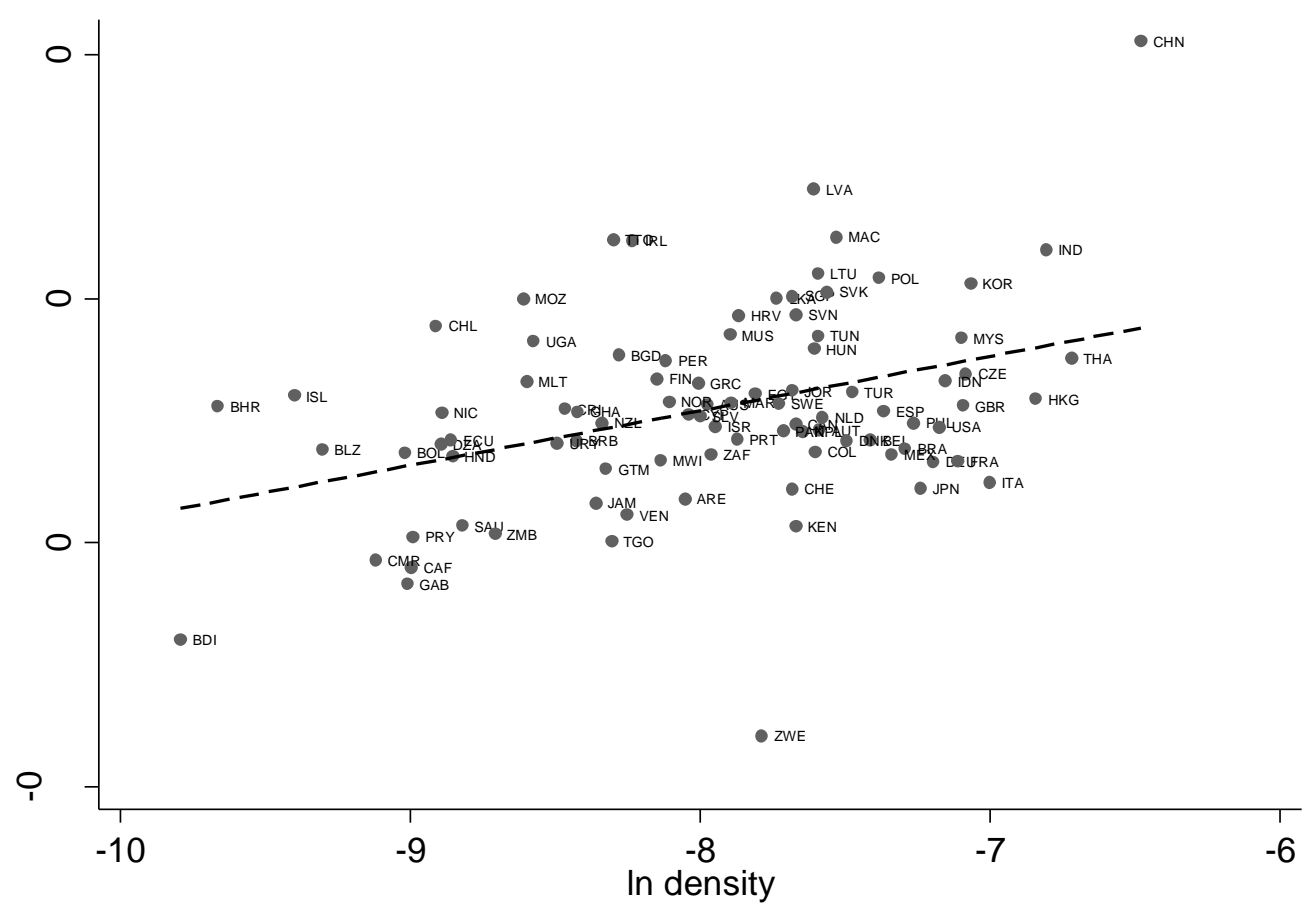

Source: authors' computations

Turning to the adaptability-growth relationship, Figure 2 shows that countries associated with a more dense occupation of the product space experienced faster growth during 1990-2009. Asian countries' sustained growth makes them cluster mostly about the upper right area of Figure 2, opposite a number of developed countries which experienced slower growth than average, such as the USA, Germany, France, the United Kingdom, Italy, and Spain.

Table 2: Growth regressions (change in lpcgdp), correlated random effects.

\begin{tabular}{|c|c|c|c|c|c|}
\hline Variable & $\begin{array}{c}\text { All } \\
\text { countries }\end{array}$ & High Income & $\begin{array}{c}\text { Middle \& } \\
\text { Low Income }\end{array}$ & \multicolumn{2}{|c|}{$\begin{array}{l}\text { All countries with } \\
\text { NTI available }\end{array}$} \\
\hline ldensity & $0.040 * * *$ & $0.039 * * *$ & $0.036 * * *$ & $0.037^{*}$ & $0.036^{*}$ \\
\hline llabf & $0.051^{*}$ & 0.081 & -0.010 & $-0.152 * *$ & $-0.151^{*}$ \\
\hline llabfpr & $-0.374 * * *$ & $-0.528 * *$ & 0.174 & -0.212 & $-0.237 *$ \\
\hline lschool & $-0.182 * * *$ & $-0.138 * *$ & $-0.225^{* * *}$ & -0.009 & -0.015 \\
\hline lpcgdp & $0.376^{* * *}$ & $0.282 * * *$ & $0.528 * * *$ & $0.296 * * *$ & $0.296 * * *$ \\
\hline $\ln t i$ & & & & & -0.003 \\
\hline constant & $0.921 * * *$ & $0.607 * * *$ & $0.411^{*}$ & $0.823^{* * *}$ & $0.899 * * *$ \\
\hline $\begin{array}{l}\text { Means of time- } \\
\text { varying variables }\end{array}$ & $\mathrm{YES} * * *$ & $\mathrm{YES} * * *$ & $\mathrm{YES} * * *$ & YES*** & YES*** \\
\hline Observations & 267 & 117 & 150 & 174 & 174 \\
\hline Countries & 89 & 39 & 50 & 58 & 58 \\
\hline Hausman Chi2 (/1) & $83.35 * * *$ & $28.75^{* * *} *$ & $60.23 * * *$ & $34.18 * * *$ & $34.43 * * *$ \\
\hline Wald Chi2 (/2) & $542.22 * * *$ & $177.64 * * *$ & $252.80 * * *$ & $126.34 * * *$ & $125.18 * * *$ \\
\hline
\end{tabular}


The growth regressions in Table 2 confirm a positive relationship between production adaptability and growth. This corroborates our growth model, which relates greater product density to a more effective accumulation of human capital. The coefficient on density is positive and significant in all the regressions, whether high income (column 2) or developing (3), and whether supply chains are controlled for (5) or not (1, 4). The process of specialization is indeed beneficial to growth, although it has a negative effect on the level of output as seen in Table 1. However, the coefficient on NTI itself is small and statistically insignificant; the role of integration into the global production networks appears to be less important for growth compared to the regressions in levels.

The finding of a robust adaptability-growth relationship across all the specifications listed in Table 2 stands out against evidence in relation to the other coefficients, which are partly inconsistent with our priors. In particular, the coefficient on schooling has a negative sign, and the labor market coefficient reverses its sign across the alternative specifications being estimated. This result is however not uncommon in the empirical growth literature, and is usually attributed to the low variance of the schooling variable once the first-difference transformation has been performed (see for instance the discussion in Arcand and d'Hombres, 2007).

All the growth regressions control for the initial level of GDP per capita, which is estimated positive and highly statistically significant. This suggests that a process of conditional convergence has not yet taken hold and may point to a dynamic instability of output per capita. Consistent with endogenous growth theory, our growth regressions emphasize the positive role of density for economic growth, because its effects seem to affect the long-run growth path of the economy, not just the transitional dynamics to a new equilibrium.

\section{Conclusions}

We analyzed the role of complexity and production adaptability on output growth, shedding light on a relationship that is under-explored in the empirical literature on cross-country differences in economic performance. In an endogenous growth model with human capital accumulation, we show that increased complexity has an ambiguous effect on the level of output, but positively impacts economic growth by enhancing human capital formation. 
Our measure of production adaptability is derived from net trade flows and is based on the product space description of the global economy disaggregated by HS product categories. The average density of a country in the product space is a measure of the adaptability of that country's production structure across sectors, which itself is the outcome of its exposure to increasingly complex production structures.

Empirical evidence from a cross-section of 89 countries and over four different time periods is fully consistent with the theoretical predictions of our model and supports the proposition that production complexity explains differences in economic performance. Our findings also suggest that the index of cross-border production fragmentation and vertical trade has a significant bearing on the regressions. This points to the need for future analysis that would incorporate more fully the vertical dimension of the product space in the endogenous growth model and rest its empirical validation on the newly defined measures and data of trade in value added (Elms and Low, 2013, Ferrarini and Hummels, 2014). 


\section{Acknowledgments}

We are very grateful to three referees and to the editor for helpful comments. We remain responsible for any mistakes.

\section{References}

ADB (2009), Nepal-Critical Development Constraints-Country Diagnostic Studies, Asian Development Bank, Department for International Development, and International Labour Organization. Mandaluyong City, Philippines: ISBN 978-971-561-803-8.

Alessandrini, M., B. Fattouh, B. Ferrarini and P. Scaramozzino (2011), "Tariff Liberalization and Trade Specialization: Lessons from India", Journal of Comparative Economics, Volume 39, Issue 4, December, pp. 499-513.

Arcand, J.-L., and B. d'Hombres (2007), "Explaining the Negative Coefficient Associated with Human Capital in Augmented Solow Growth Regressions", JCR Scientific and Technical Reports, European Commission.

Balassa, B. (1965), "Trade Liberalization and 'Revealed' Comparative Advantage", The Manchester School of Economic and Social Studies, Vol. 32, No. 2, pp. 99-123.

Barro, R., and J.-W. Lee (2010), "A New Data Set of Educational Attainment in the World, 1950-2010”, NBER Working Paper No. 15902, April.

Bugamelli, M. (2001), 'Il Modello di Specializzazione Internazionale dell'Area dell'Euro e dei Principali Paesi Europei: Omogeneità e Convergenza", Temi di Discussione 402, Banca d'Italia, Rome.

Costinot, A. (2009), "On the Origins of Comparative Advantage", Journal of International Economics, Vol. 77, pp. 255-264.

Dalmazzo, A., T. Pekkarinen and P. Scaramozzino (2007), "O-Ring Wage Inequality", Economica, Vol. 4, no. 295, August 2007, pp. 515-536.

Duernecker, G., M. Meyer and F. Vega-Redondo (2012), "Being Close to Grow Faster: A Network-Based Empirical Analysis of Economic Globalization", Department of Economics, European University Institute, EUI Working Paper No. 2012/05.

Elms, D.K. and P. Low (2013), Global Value Chains in A Changing World, World Trade Organization, Fung Global Institute, and Temasek Foundation Centre For Trade \& Negotiations, Geneva: WTO Publications, ISBN: 978-92-870-3882-1.

Felipe, J., U. Kumar, A. Abdon, and M. Bacate (2012), "Product Complexity and Economic Development", Structural Change and Economic Dynamics, Vol.23, Issue 1, March, pp. 36-68.

Ferrarini, B. (2013), "Vertical Trade Maps", Asian Economic Journal, Vol. 27, No. 2, pp. $105-123$.

Ferrarini, B., and D. Hummels (eds.) (2014), Asia and Global Production Networks, Cheltenham, UK and Northampton, USA, Edward Elgar.

Ferrarini, B., and P. Scaramozzino (2015), "The Product Space Revisited: China's Trade Profile", The World Economy, Vol 8, Issue 9, September, pp. 1368-1386.

Hausmann, R., J. Hwang and D. Rodrik (2007), "What You Export Matters", Journal of Economic Growth, Vol. 12, pp. 1-25.

Hausmann, R., and B. Klinger (2006), "Structural Transformation and Patterns of Comparative Advantage in the Product Space", Centre for International Development, Harvard University, Working Paper No. 128.

Hausmann, R., and B. Klinger (2007), "The Structure of the Product Space and the Evolution of Comparative Advantage", Centre for International Development, Harvard University, Working Paper No. 146. 
Hidalgo, C. A. (2009), "The Dynamics of Economic Complexity and the Product Space over a 42 Year Period", Centre for International Development, Harvard University, Working Paper No. 189.

Hidalgo, C. A., and R. Hausmann (2009), "The Building Blocks of Economic Complexity", Proceedings of the National Academy of Sciences, Vol. 106, No. 26, June 30, pp. 10570-10575.

Hidalgo, C. A., B. Klinger, A.-L. Barabási and R. Hausmann (2007), “The Product Space Conditions the Development of Nations", Science, Vol. 317, 27 July, pp. 482-487.

Hirschman, A. (1958), The Strategy of Economic Development, New Haven, Conn., Yale University Press.

Kaldor, N. (1967), Strategic Factors in Economic Development, New York State School of Industrial and Labor Relations, Cornell University, Ithaca, NY.

Koopman, R., Wang, Z., and Wei, S.-J. (2008) "How Much of Chinese Exports is Really Made In China? Assessing Domestic Value-Added When Processing Trade is Pervasive", NBER Working Papers 14109, National Bureau of Economic Research, Inc, June 2008.

Kremer, M. (1993), “The O-Ring Theory of Economic Development”, Quarterly Journal of Economics, Vol. 108, pp. 551-575.

Lafay, G. (1992), "The Measurement of Revealed Comparative Advantage", in M. G. Dagenais and P. A. Muet (eds), International Trade Modelling, London, Chapman \& Hall.

Lall, S. (1992), "Technological Capabilities and Industrialization", World Development, Vol. 20, pp. 165-188.

Lewis, A. (1955), The Theory of Economic Growth, Irwin, Homewood, IL.

Lucas, R. E. Jr. (1988), “On the Mechanics of Economic Development”, Journal of Monetary Economics, Vol. 22, pp. 3-42.

Lucas, R. E. Jr. (1993), "Making a Miracle”, Econometrica, Vol. 61, No. 2, March, pp. 251272.

Poncet, S. and F.S. de Waldemar (2013), "Complexité Économique et Croissance: Une Application au Cas Chinois", Revue Économique, Vol. 64, No.3, pp. 495-503.

Romer, P.M. (1989) "What Determines the Rate of Growth and Technological Change?," Policy Research Working Paper Series, No. 279, The World Bank.

Rostow, W.W. (1959), "The Stages of Economic Growth", Economic History Review, Vol.12, Issue 1, pp. 1-16.

Smith, A. (1776), The Wealth of Nations, London, W. Strahan and T. Cadell.

Solow, R.M. (1956), "A Contribution to the Theory of Economic Growth", The Quarterly Journal of Economics, Vol. 70, No. 1, pp. 65-94.

Sutton, J. (2001), "Rich Trades, Scarce Capabilities: Industrial Development Revisited”, LSE STICERD Research Paper No. E1 28.

Wang. Z., S.J. Wei and A. Wong (2010), "Does a Leapfrogging Growth Strategy Raise Growth Rate? Some International Evidence", NBER Working Paper No. 16390, September 2010.

Wooldridge, J. (2010), Econometric Analysis of Cross Section and Panel Data, 2nd ed., Cambridge (MA), MIT Press.

Zaghini, A. (2005), "Evolution of Trade Patterns in the New EU Member States", Economics of Transition, 13(4), pp. 629-658.

Zuleta, H. (2004), “A Note on Scale Effects”, Review of Economic Dynamics, Vol. 7, Issue 1, January, pp. 237-242. 


\section{Data Appendix}

\section{Countries included in the analysis (World Bank ISO codes)}

High-income countries:

ARE, AUS, AUT, BEL, BHR, BRB, CAN, CHE, CYP, CZE, DEU, DNK, ESP, FIN, FRA, GBR, GRC, HKG, HRV, HUN, IRL, ISL, ISR, ITA, JPN, KOR, MAC, MLT, NLD, NOR, NZL, PRT, SAU, SGP, SVK, SVN, SWE, TTO, USA.

Middle- and low-income countries:

BDI, BGD, BLZ, BOL, BRA, CAF, CHL, CHN, CMR, COL, CRI, DZA, ECU, EGY, GAB, GHA, GTM, HND, IDN, IND, JAM, JOR, KEN, LKA, LTU, LVA, MAR, MEX, MOZ, MUS, MWI, MYS, NIC, NPL, PAK, PER, PHL, POL, PRY, SLV, TGO, THA, TUN, TUR, UGA, URY, VEN, ZAF, ZMB, ZWE.

\section{Definitions and sources of variables}

\begin{tabular}{|c|c|c|}
\hline Variable Name & Description & Source \\
\hline$l p c g d p$ & $\begin{array}{l}\text { Logarithm of GDP per capita, current US\$ } \\
\text { (5-year period averages) }\end{array}$ & $\begin{array}{l}\text { Authors' computation, based } \\
\text { on World Development } \\
\text { Indicators, The World Bank } \\
\text { Group }\end{array}$ \\
\hline$l d p c g d p$ & $\begin{array}{l}\text { Logarithm of 5-year compound annual } \\
\text { growth rates of GDP per capita }\end{array}$ & $\begin{array}{l}\text { Authors' computation, based } \\
\text { on World Development } \\
\text { Indicators, The World Bank } \\
\text { Group }\end{array}$ \\
\hline ldens & $\begin{array}{l}\text { Logarithm of } 5 \text {-year average product } \\
\text { density by country and year, according to } \\
\text { the Lafay product space definition }\end{array}$ & $\begin{array}{l}\text { Authors' computation, based } \\
\text { on Ferrarini and } \\
\text { Scaramozzino (2015) }\end{array}$ \\
\hline llabf & $\begin{array}{l}\text { Logarithm of total active population ( } 15 \\
\text { years and older), thousands }\end{array}$ & $\begin{array}{l}\text { Key Indicators of the Labor } \\
\text { Market, International Labor } \\
\text { Organization (ILO) }\end{array}$ \\
\hline llabfpr & $\begin{array}{l}\text { Logarithm of labor force participation } \\
\text { rate, percent }\end{array}$ & $\begin{array}{l}\text { Key Indicators of the Labor } \\
\text { Market, International Labor } \\
\text { Organization (ILO) }\end{array}$ \\
\hline lschool & $\begin{array}{l}\text { Logarithm of total years of schooling (15 } \\
\text { years and older), units }\end{array}$ & Barro and Lee (2010) \\
\hline $\ln t i$ & Logarithm of Network Trade Index (NTI), & Ferrarini (2013) \\
\hline
\end{tabular}


units

Matrix of pair-wise correlations $(* \mathbf{p}<0.05)$

\begin{tabular}{l|rrrrrr} 
& lpcgdp & ldens & llabf & llabfpr & lschool & lnti \\
\hline ldens & $0.2511^{*}$ & & & & & \\
llabf & $-0.1777^{*}$ & $0.5403^{*}$ & & & & \\
llabfpr & $-0.3628^{*}$ & $-0.2649^{*}$ & -0.0091 & & & \\
lschool & $0.7527^{*}$ & $0.2520^{*}$ & $-0.1481^{*}$ & $-0.3683^{*}$ & & \\
lnti & $0.4093^{*}$ & $0.7781^{*}$ & $0.3128^{*}$ & 0.0681 & $0.3165^{*}$ & \\
ldpcgdp & $0.1586^{*}$ & $0.2804^{*}$ & 0.0865 & $-0.1667^{*}$ & $0.1529^{*}$ & $0.1877^{*}$
\end{tabular}

Summary statistics

\begin{tabular}{l|rrrrr} 
Variable & Obs & Mean & Std. Dev. & Min & Max \\
\hline lpcgdp & 355 & 8.26 & 1.56 & 4.70 & 10.63 \\
ldens & 355 & -7.96 & 0.75 & -11.14 & -6.42 \\
llabf & 355 & 15.46 & 1.68 & 11.14 & 20.46 \\
llabfpr & 355 & 4.13 & 0.14 & 3.84 & 4.51 \\
lschool & 355 & 1.96 & 0.42 & -0.26 & 2.55 \\
lnti & 232 & 0.30 & 1.27 & -4.60 & 2.67 \\
ldpcgdp & 267 & 0.11 & 0.10 & -0.40 & 0.58
\end{tabular}

